\section{RECORD OF THE GENUS ARRHENOPHAGOIDEA GIRAULT (HyMenOPTERA: ChALCIDOIDEA: ENCYRTIDAE) From INDIA, DESCRIPTION OF A NEW SPECIES FROM THE ANDAMAN ISLANDS}

\author{
Mohammad Hayat ${ }^{1}$ \& $\mathrm{K}$. Veenakumari ${ }^{2}$ \\ ${ }^{1}$ Department of Zoology, Aligarh Muslim University, Aligarh, Uttar Pradesh 202002, India \\ ${ }^{2}$ National Bureau of Agriculturally Important Insects, Bengaluru, Karnataka 560024, India \\ ${ }^{1}$ hayat.mohd44@gmail.com (corresponding author), ${ }^{2}$ veenaprashi@rediffmail.com
}

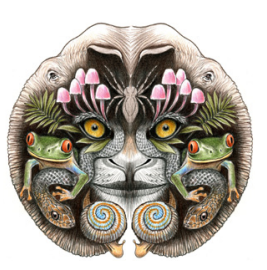

ISSN

Online 0974-7907

Print 0974-7893

\begin{abstract}
The genus Arrhenophagoidea Girault (Hymenoptera: Encyrtidae) is recorded for the first time from India and the Orienta region, and a new species, $A$. andamanica sp. nov. is described from material collected in the Andaman and Nicobar Islands, India. As the genus is newly recorded from the Oriental region, a brief diagnosis is also given.
\end{abstract}

Keywords: Arrhenophagoidea, Encyrtidae, Hymenoptera, India, new record, new species, Oriental region.

Abbreviations: F1, F2, etc. - funicle segment 1, 2, etc.; OOL - minimum distance between a posterior ocellus and the corresponding eye margin; POL - minimum distance between the posterior ocelli; TVII Tergite 7 of gaster; (YPT) - This abbreviation placed in brackets and used under 'Material examined' section to indicate that the specimens were collected in a yellow pan trap; NBAll - National Bureau of Agriculturally Important Insects, Bengaluru, India; ZDAMU - Insect Collections, Department of Zoology, Aligarh Muslim University, Aligarh, India.

Arrhenophagoidea Girault (1915) is a little-known genus, containing five species (Noyes 2013); the type species, A. coloripes Girault (1915) from Australia, and four South African species (A. chaetacmae Annecke \& Prinsloo, 1974; A. neseri Prinsloo, 1974; A. rolaspidis Annecke \& Prinsloo, 1974; A. sierra Annecke \& Prinsloo,
1974). Species of this genus, where hosts are known, are parasitoids of armoured scale insects (Hemiptera: Diaspididae).

In a recent collection of Encyrtidae (and other Hymenoptera) made by the second author in the Andaman and Nicobar Islands, some specimens of the genus Arrhenophagoidea were found. These proved to belong to an undescribed species, and are described here in this paper. It is to be noted that Arrhenophagoidea is recorded here for the first time not only from India but also from the Oriental region.

\section{Methods}

Body colour was noted from card mounted specimens prior to mounting the specimens on slides in Canada balsam. Only body lengths are given in millimetres; all other measurements are relative, taken from the divisions of the linear scale of an ocular micrometer placed in the eye piece of a compound microscope. All the measurements were taken at $400 \times$ magnification of the microscope.

DOI: http://dx.doi.org/10.11609/JoTT.03675.5769-73 | ZooBank: urn:Isid:zoobank.org:pub:A5E8F2OF-DCAE-4C12-83BB-AF8A1FFFF5D1

Editor: John Noyes, Natural History Museum, London, UK.

Date of publication: 26 May 2014 (online \& print)

Manuscript details: Ms \# 03675 | Received 22 June 2013 | Final received 22 April 2014 | Finally accepted 27 April 2014

Citation: Hayat, M. \& K. Veenakumari (2014). Record of the genus Arrhenophagoidea Girault (Hymenoptera: Chalcidoidea: Encyrtidae) from India, description of a new species from the Andaman Islands. Journal of Threatened Taxa 6(5): 5769-5773; http://dx.doi.org/10.11609/JoTT.o3675.5769-73

Copyright: (C) Hayat \& Veenakumari 2014. Creative Commons Attribution 4.0 International License. JoTT allows unrestricted use of this article in any medium, reproduction and distribution by providing adequate credit to the authors and the source of publication.

Funding: Indian Council of Agricultural Research.

Competing Interest: The authors declare no competing interests.

Acknowledgements: The first author (MH) thanks the Indian Council of Agricultural Research, New Delhi, and Dr. V.V. Ramamurthy (Division of Entomology, Indian Agricultural Research Institute, New Delhi), the National co-ordinator of the "Network Project on Insect Biosystematics", for financial help. He also thanks the Chairman, Department of Zoology, Aligarh Muslim University, Aligarh, for providing facilities. The second author (KV) is thankful to the Director, National Bureau of Agriculturally Important Insects, Bengaluru, for encouragement. We thank Dr. S.B. Zeya, Associate Professor, Department of Zoology, A.M.U., for the digital images. 


\section{Arrhenophagoidea Girault}

Arrhenophagoidea Girault, 1915: 73. Type species Arrhenophagoidea coloripes Girault, by monotypy and original designation.

\section{Diagnosis}

Female: Head with occipital margin sharp; frontovertex width at least $0.5 \times$ head width; ocellar triangle with apical angle obtuse; head, in frontal view, with frontovertex separated from facial region by a transverse membranous line; mouth margin emarginated at bases of mandibles; antennal torulus separated from mouth margin by the height of a torulus. Mandible with a single, slightly curved and pointed tooth or two blunt teeth, sometimes with indication of a short, receding dorsal truncation. Maxillary palp 2- or 3-segmented; labial palp unsegmented. Antenna with funicle segments (3-6) transverse, usually adpressed with base of clava; clava either solid (= unsegmented) or with 2-3 segments, the septa separating claval segments either complete or incomplete; apex of clava from slightly to distinctly obliquely truncate. Fore wing broad; submarginal vein in proximal half with one or two setae; parastigma with one seta; marginal vein with two setae; stigmal vein with four circular sensilla; otherwise, limits of marginal vein obscured by infuscation. Legs with tarsal formula, 5-5-5. Metasoma subequal in length to mesosoma; ovipositor with third valvula (= gonostylus) in membranous connection with second valvifer.

Male: Similar to female, except for the antenna and genitalia. Antenna with 9-10 segments; funicle segments (5 or 6 ) usually quadrate to slightly longer than broad; clava either solid or 2-segmented; funicle segments with whorls of long setae. Genitalia with phallobase cylindrical, anteriorly narrowed; parameres absent; digiti long, and each digitus with two short denticles; aedeagus longer than phallobase. [Although males are known for all the five described species, the genitalia were neither described nor illustrated earlier by the authors.]

Comments: The genus Arrhenophagoidea is apparently very similar to Arrhenophagus Aurivillius (Annecke \& Prinsloo, 1974; Noyes \& Hayat 1984), but differs in having the tarsi 5-segmented. In Arrhenophagus, the tarsi are 4-segmented.

\section{Arrhenophagoidea andamanica Hayat, sp. nov.} (Figs. 1-7; Images 1-8)

urn:Isid:zoobank.org:act:2286579B-5F39-4421-8125-22043DA0E044

\section{Material examined}

Holotype: (NBAll \# ICAR/NBAII/EN15), female (on slide under four coverslips, slide No. EH.1658), 26.i.2013 (YPT), CARI [Central Agricultural Research Institute], South Andaman, Port Blair, Andaman \& Nicobar Islands, India, coll. K. Veenakumari.

Paratypes: 10 females, five males. Three females, four males (two females, one male, on slides, nos. EH.1653, EH.1657, EH.1652), with data same as for holotype; three females (slides, EH.1650, EH.1661, EH.1672), 26.i.2013, South Andaman, Garacharma, coll. K. Veenakumari; four females (slides, EH.1651, EH.1660, EH.1663, EH.1671), 31.i.2013, Garacharma, coll. K. Veenakumari; one male (slide, EH.1656), 30.i.2013, Little Andaman, Forest Nursery, coll. K. Veenakumari; (five females, one male slides, EH.1651-EH.1653, EH.1663, EH.1671, EH.1672, in ZDAMU, no. HYM.CH.667; four females, one male, on slides, and one female, three males on two cards, in NBAII, nos. ICAR/NBAII/EN16-22).

\section{Etymology}

The species name is derived from the name of the group of islands (Andamans) from where the specimens were collected.

\section{Description}

Female. Holotype. Length, 0.49mm (paratypes, 0.47$0.53 \mathrm{~mm}$ ). Head dark brown. Antenna pale yellowishwhite. Mesosoma dark brown. Fore wing hyaline, with a triangular patch at base, a light streak at level of parastigma and around distal veins, infuscated; hind wing hyaline. Legs with coxae dark brown; femora, except white bases and apices, dark brown; tibiae and tarsi whitish. Metasoma dark brown; apex of TVII of gaster white; third valvula dark brown.

Head (Image 1): Head with frontovertex width $0.55 \times$ head width; ocellar triangle with apical angle obtuse; posterior ocellus about half diameter of an ocellus to occipital margin; POL, 24; OOL, 8.5; head, in frontal view, $1.2 \times$ as broad as high; antennal torulus with upper margin slightly below lower margin of eye, and each torulus separated from mouth margin by about the height of a torulus; malar space $0.76 \times$ eye height; frontovertex with fine, polygonal reticulate sculpture up to transverse membranous line; below this line with obliquely oriented, elongate reticulate sculpture; malar space with lineolate reticulate sculpture; setae on head brown; 


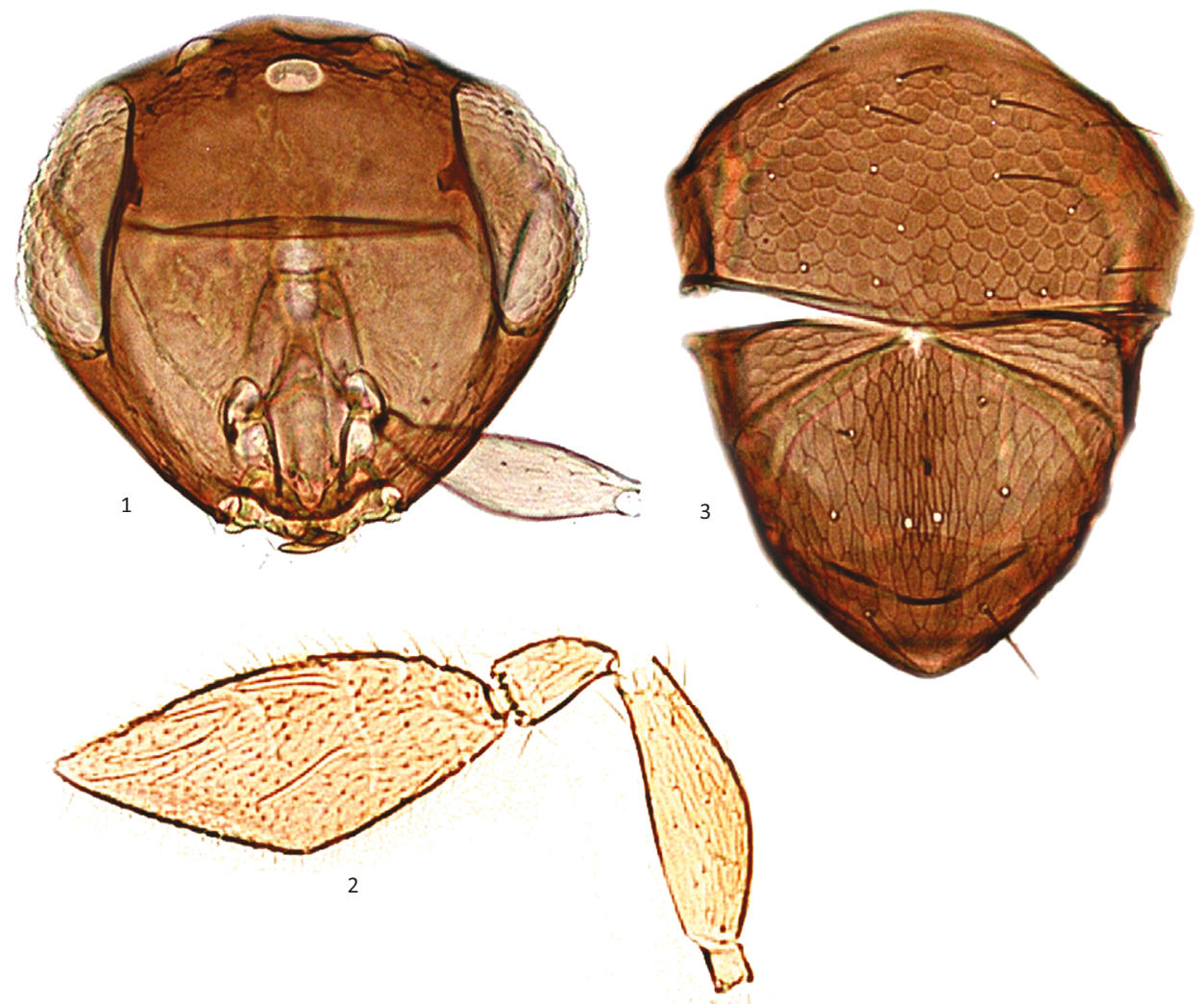

Images 1-3. Arrhenophagoidea andamanica Hayat sp. nov., female.

1 - head, frontal view; 2 - antenna; 3 - mesothoracic dorsum. (Image 2 from holotype) (@ Dr. S.B. Zeya)

eyes setose, setae hyaline, and each seta slightly shorter than a facet diameter. Maxillary palp 3-segmented, first segment quadrate to slightly broader than long; labial palp unsegmented (Fig. 3). Mandible with an apically curved and pointed tooth and a small, receding dorsal truncation (Figs. 1, 2). Antenna (Image 2) with scape $0.72 \times$ frontovertex width; scape $2.85 \times$ as long as broad; pedicel $0.4 \times$ scape length; funicle with 3 segments (F13), each segment transverse, F3 $1.8 \times$ as broad as F1; F3 adpressed with base of clava; clava large, $1.22 \times$ as long as scape, $1.92 \times$ as long as broad, with a strong oblique truncation, truncate part $0.71 \times$ clava length; clava with two incomplete sutures on its inner surface only (Figs. 4,5). Relative measurements (holotype, slide): head frontal width, 100; head frontal height, 83; frontovertex width, 55; mouth fossa width, 32; eye height, 46; malar space, 35; antennal scape length (width), 40 (14); pedicel length (width), 16.5 (11.5); funicle length, 11; F1 width, 10; F3 width, 18; clava length (width), 49 (25.5).

Mesosoma: Mesothoracic dorsum as in Image 3; pronotum with raised reticulate sculpture; mesoscutum with regular polygonally reticulate sculpture; scutellum in about median fifth with fine, elongate reticulate sculpture, laterally with cells larger, and slightly longitudinally elongated (Image 3); setae brown; in holotype mesoscutum with 16 setae, each axilla with two setae and scutellum with 6 setae $[3+3$; left half 3 setae, and right half three setae]. Fore wing (Image 4) 2.29x as long as broad; marginal fringe short, about $0.12 \times$ wing width; submarginal vein with two setae in proximal half, and parastigma proximally with one long seta; marginal vein with two setae; linea calva interrupted posteriorly by about three lines of setae, and proximally with at least 35 setae. Hind wing (Image 5) 5.66x as long as broad; marginal fringe $0.7 \times$ wing width. Mid tibia and tarsus as in Image 6; mid tibial spur slightly longer than mid basitarsus. Relative measurements (holotype, slide): fore wing length (width), 220 (96); hind wing length (width), 136 (24); mid tibia length, 72; mid basitarsus length, 14; mid tibial spur length, 16.

Metasoma: Ovipositor as in Image 7; hypopygium as in Figure 6. Relative measurements (holotype, slide): TVII length, 55; ovipositor length, 75; third valvula length, 25.

Male: Similar in colour, sculpture and dimensions of various body parts to female except for the antenna and genitalia. Antennal torulus with upper margin in line 

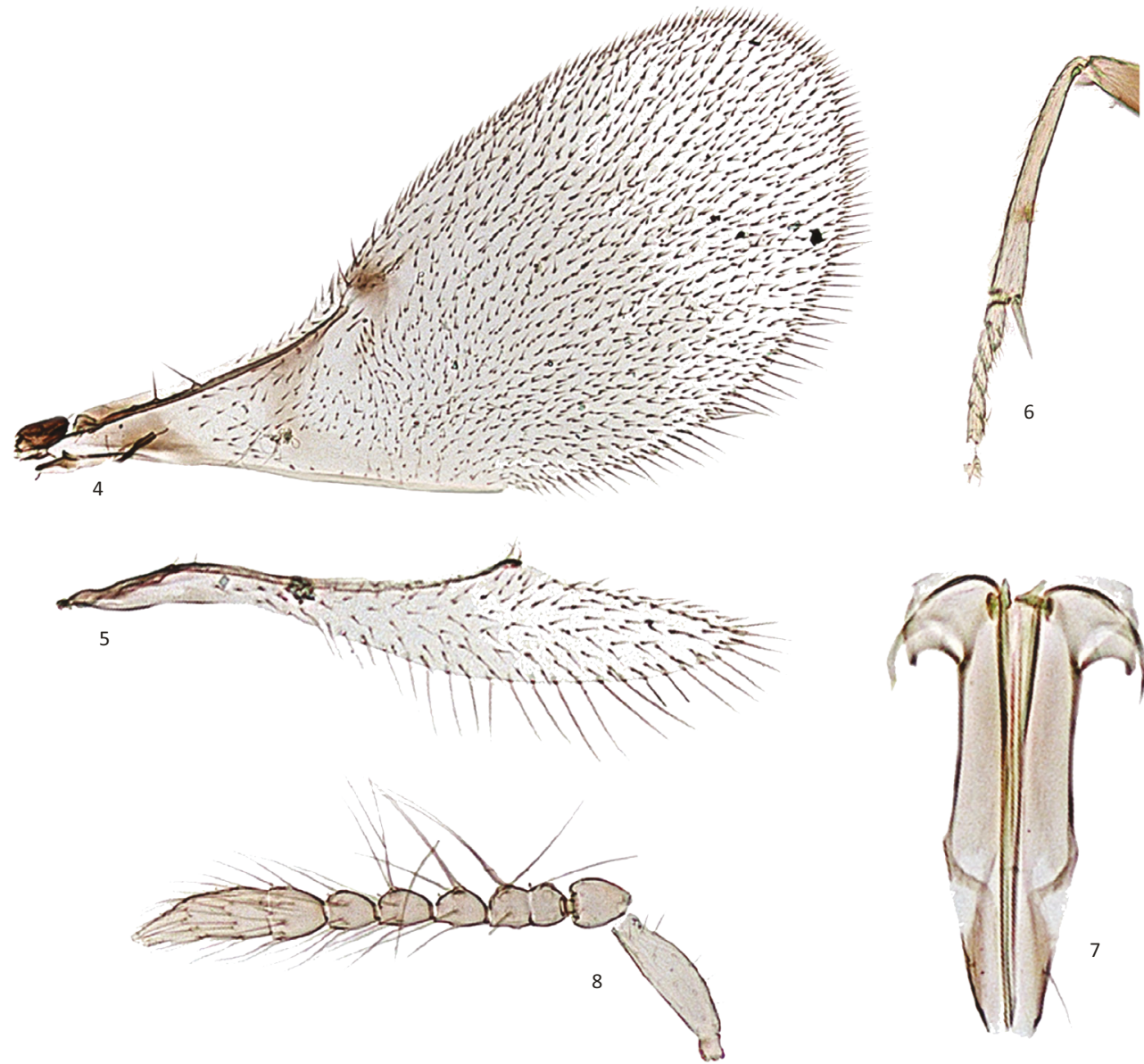

Images 4-8. Arrhenophagoidea andamanica Hayat sp. nov., female except image 8.

4 - fore wing; 5 - hind wing; 6 - mid tibia and tarsus; 7 - ovipositor; 8 - male antenna. (Images 4, 5 and 6 from holotype) (@ Dr. S.B. Zeya)

with or slightly above, lower margin of eye. Antenna (Image 8) with a 5-segmented funicle and a 2-segmented clava, but the funicle may appear 6-segmented and the clava solid; F1 and F2 separated by a suture. Genitalia (in 2 specimens on slides) with aedeagus $1.55 \times$ as long as phallobase; phallobase $0.52 \times$ and $0.55 \times$ mid tibia length; each digitus about $0.26 \times$ phallobase length, and provided with two short denticles (Fig. 7).

Variation: Body length varies from $0.47-0.53 \mathrm{~mm}$. In paratypes, the number of setae on each axilla and the scutellum vary: each axilla with two setae in two specimens, but one long seta in five specimens; in one specimen two setae on the left axilla and one seta on the right axilla. Similarly, scutellum with six $(=3+3)$ setae in five specimens; in one specimen, $4+4$ setae; in one specimen $3+4$ setae, and in another specimen, $4+3$ setae.

Comments: This new species appears similar to Arrhenophagoidea chaetacmae Annecke \& Prinsloo (1974) in having six setae on the scutellum, but differs in having three distinct funicle segments, incomplete first and second suture of the clava; scutellum with longitudinally elongate sculpture in about median fifth, and laterally with elongate, large cells; head with the membranous line very narrow; fore wing with two setae on the submarginal vein; basal triangle proximal to the linea calva with relatively more setae (at least 35 ); third valvula $1.56 \times$ as long as mid tibial spur. (In A. chaetacmae: the three funicle segments "very indistinct in most cleared specimens"; clava with one complete suture and the second suture incomplete; scutellum with fine, longitudinally elongate cells; head with the transverse membranous line "broader and more conspicuous"; forewing with one long seta on the submarginal vein; basal triangle proximal to the linea calva with fewer setae (about 16); third valvula "only slightly longer than middle tibial spur". Based on the original description and figures 22-25 given by Annecke \& Prinsloo 1974).

The new species is also similar to $A$. coloripes Girault (1915) (Based on the brief notes and figures given by Annecke \& Prinsloo 1974: figs. 15 and 16), but differs in 


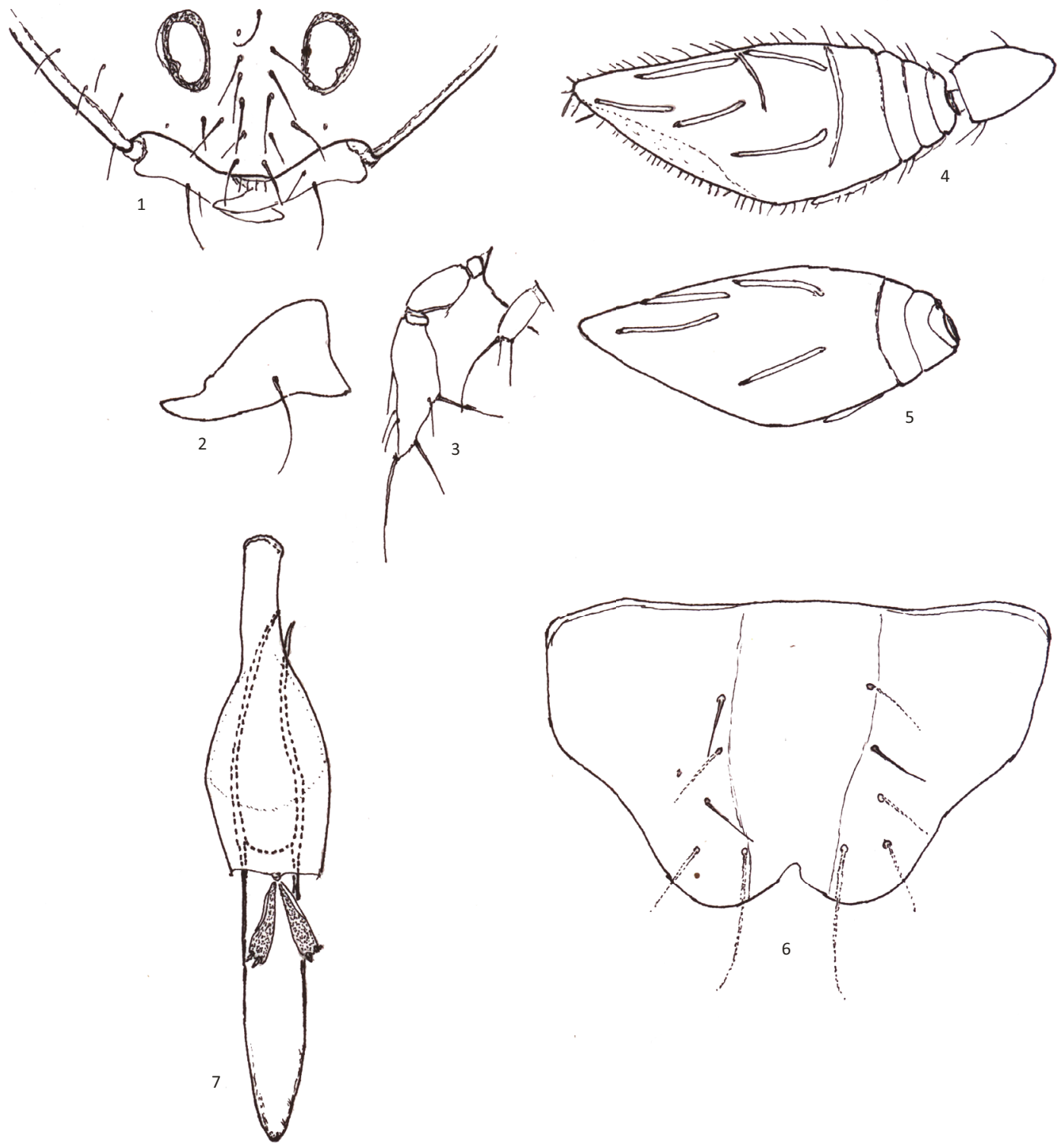

Figures 1-7. Arrhenophagoidea andamanica Hayat sp. nov., female except figure 7.

1 - mouth region; 2 - mandible; 3 - maxillary and labial palps; 4 - pedicel and flagellum, inner aspect; 5 - flagellum, outer aspect; 6 - hypopygium; 7 - male genitalia. (Figures 4 and 5 from holotype)

having the body size $0.47-0.53 \mathrm{~mm}$; mandible with one pointed tooth and a small receding dorsal truncation; antennal scape less than $3 \times(2.85 \times)$ as long as broad; antennal clava with two incomplete sutures on its inner side; and scutellum normally with six setae [see variation noted above in the number of scutellar setae]. (In $A$. coloripes: body size $0.85 \mathrm{~mm}$; mandible with a single pointed tooth; antennal scape $3.5 \times$ as long as broad; clava solid; and scutellum with 8 setae.).

\section{References}

Annecke, D.P. \& G.L. Prinsloo (1974). On some new and described species of arrhenophagine Encyrtidae (Hymenoptera). Journal of the Entomological Society of southern Africa 37: 35-47.

Girault, A.A. (1915). Australian Hymenoptera Chalcidoidea - VII. The family Encyrtidae with descriptions of new genera and species. Memoirs of the Queensland Museum 4: 1-184.

Noyes, J.S. (2013). Universal Chalcidoidea Database. Electronic publication. www.nhm.ac.uk/research-curation/projects/chalcidoids (Accessed 08 June 2013)

Noyes, J.S. \& M. Hayat (1984). A review of the genera of Indo-Pacific Encyrtidae (Hymenoptera: Chalcidoidea). Bulletin of the British Museum (Natural History) (Entomology) 48: 131-395.

Prinsloo, G.L. (1974). A new species of Arrhenophagoidea Girault, 1915 (Hymenoptera: Encyrtidae) from South Africa. Journal of the Entomological Society of southern Africa, 37: 257-260. 